\title{
Microstructure and Some Characteristics of Copper-Graphene Nanocomposites Synthesized by Powder Technology
}

\author{
Aqeel Hadi $\mathrm{Ali}^{1}$, and Mohsin Talib Mohammed ${ }^{1 *}$ \\ ${ }^{1}$ Materials Engineering Department, Faculty of Engineering, University of Kufa, Najaf, Iraq
}

\begin{abstract}
In recent years, nano-scale graphene $(\mathrm{Gn})$ has generated a lot of interest owing to its remarkable characteristics, which made it a material of choice for reinforcing different kinds of materials for a broad range of engineering applications. In this study, a serious attempt has been paid to develop copper-graphene $(\mathrm{Cu} / \mathrm{Gn})$ nanocomposites by powder technology process using different concentrations of $\mathrm{Gn}$. Also, microstructure, thermal, micro-hardness and wear properties have been studied.
\end{abstract}

\section{Introduction}

It is well known that copper $(\mathrm{Cu})$ and its alloys have been widely used as structural materials for many engineering applications owing to their outstanding thermal and electrical conductivities and chemical stability [1]. However, they display relatively poor mechanical properties, particularly at higher temperature, which significantly restricts their applications [2]. Therefore, the development of the performance of $\mathrm{Cu}$ and its alloys became an imperative issue in order to meet the industrial challenges in several industries such as machinery, electronic, transport and others. The most effective strategy to attain higher performance is the introducing of secondary phase in $\mathrm{Cu}$ matrix to fabricate $\mathrm{Cu}$-matrix composites (CMCs) $[3,4]$. The main advantages involve high thermal and electrical conductivities, along with excellent mechanical performance and processing properties $[5,6]$. Recently, nano-scale $\mathrm{Gn}$ and its derivatives have generated a lot of interest for reinforcing $\mathrm{Cu}$ matrix owing to their remarkable characteristics such as high thermal conductivity (in-plane: $4000-5000 \mathrm{~W} / \mathrm{m} . \mathrm{K}$ and throughplane: 10-20 W/m.K) [7], outstanding mechanical strength [8], electrical conductivity [9], as well as great specific area (SSA-500-1200 m²/g) [10]. Therefore, several investigations and researches have focused on $\mathrm{Gn}$ as a potential reinforcement for $\mathrm{Cu}$ matrix composites [11-15]. However, strengthening of $\mathrm{Cu}$ matrix with Gn particles is still seldom and needs a lot of studies. In the present work, a serious attempt has been paid to successfully fabricate $\mathrm{Cu} / \mathrm{Gn}$ nanocomposites by conventional powder metallurgy process using different amounts of $\mathrm{Gn}$. The microstructure, thermal, micro-hardness, and wear properties are also analysed.

\footnotetext{
* Corresponding author: mohsint.alyasiri@uokufa.edu.iq
}

\section{Materials and methods}

In this study, two main types of materials are used namely as received pure $\mathrm{Cu}$ with $>99.5 \%$ purity and manufactured by a company (Chem-Lab NB, Belgium), and the $G$ platelet nanopowder (Skyspring nanomaterial, USA- thickness: $6-8 \mathrm{~nm}$, average particle diameter: $15 \mu \mathrm{m}$, surface area: $120-150 \mathrm{~m} 2 / \mathrm{g}$ and carbon $(\%)$ : $>99.5$.

A powder metallurgy process was adopted to produce $\mathrm{Cu} / \mathrm{Gn}$ nanocomposites with variable percentages of the Gn particles. Using a sensitive balance, weight percentages of $\mathrm{Gn}$ particles $(0.5$ and $1 \mathrm{wt} \%)$ were precisely weighed and added to the $\mathrm{Cu}$ matrix powder in order to produce various $\mathrm{Cu} / \mathrm{Gn}$ nanocomposite samples. Afterwards, the powder samples were mixed by the mechanical mixing device The mixing was done using balls of zirconium for 3.5 hours to confirm uniform mixing. The process was stopped for $15 \mathrm{~min}$ after every half hour of mixing to prevent the increase in the mixing temperature which may cause an agglomeration of Gn within the structure of produced nanocomposites. Different size balls of zirconium were placed in the mixing bowl and the ball-to-powder ratio was fixed as 10:1 to increase the mixing efficiency. After completing mixing step, the blended powders were cold pressed using a closed cylindrical die in a hydraulic press. The uniaxial pressure of pressing was kept at $600 \mathrm{MPa}$ and the speed of the piston was determined first before the start of the pressure process; it was kept at $0.5 \mathrm{~mm} / \mathrm{min}$ to avoid overheating of the material. The produced pellets had a diameter of $16 \mathrm{~mm}$ and height of $8 \mathrm{~mm}$. Before pressing step, the die wall and punch is lubricated with paraffin oil to prevent green compact samples from sticking to the die. The conventional sintering process of green samples was carried out using a tubular furnace. The process was 
performed at $800^{\circ} \mathrm{C}$ in argon gas atmosphere with a heating rate of $10{ }^{\circ} \mathrm{C} / \mathrm{min}$ and holding time of $60 \mathrm{~min}$. The sintered samples were then permitted to cool naturally inside the furnace.

Optical microscopy micrographs of the pure $\mathrm{Cu}$ and $\mathrm{Cu} / \mathrm{Gn}$ nanocomposite samples were taken using the linear cross-section method by an optical microscope. Conventional metallographic procedures were carried out for the sintered samples in order to obtain the optical micrographs. The grinding was done using different grades of SiC emery papers $(200,400,600,800,1000$, 1200, 200 and 2500). Afterwards, the samples were polished for obtaining a mirror surface finish using a special softening cloth and aqueous diamond medium (particle size of $1 \mu \mathrm{m}$ ) suspended in water. The etching of the samples was accomplished depending upon ASTM E407 standard using a pre-prepared solution (5 g $\mathrm{FeCl}_{3}, 10 \mathrm{ml} \mathrm{HCl}, 30 \mathrm{ml}$ water and $50 \mathrm{ml}$ glycerol [16]. The polished samples were etched by swabbing using cotton soaked with etchant for a time period of 15-20 seconds. Finally, the eached samples was washed with distilled water, dried and kept carefully for obtaining microstructural micrographs. An energy dispersive Xray spectrometer (EDS) attached to SEM device (Inspect S50, SEM.FEI, Holland) was also used to detect the major elements in the produced nanocomposite samples. The density of sintered samples was determined using a manner based on Archimedes rule. Vickers micro-hardness of pure $\mathrm{Cu}$ and $\mathrm{Cu} / \mathrm{Gn}$ nanocomposite samples was measured using an automatic micro-hardness tester (TH715, Beijing Time High Technology Ltd, China) with an attached microscope of a total amplification of 400X. The load of $100 \mathrm{~g}$ and a dwelling time of 10 seconds were applied in this test. The test was repeated five times in different points for each sample in order to include both the matrix and the reinforcement area and in turn to obtain an accurate measurement; the average of readings was taken. The wear test for pure $\mathrm{Cu}$ and $\mathrm{Cu} / \mathrm{Gn}$ nanocomposite samples was carried out by dry sliding wear approach according to ASTM G99 standard [17]. A room temperature wear test was performed using a locally-made pin-on-disk sliding wear tester. Also, the wear test was examined on standard cylindrical samples with a height of $30 \mathrm{~mm}$ and diameter of $16 \mathrm{~mm}$. The test was carried out at an applied normal force of $20 \mathrm{~N}$, a rotation speed of $950 \mathrm{rpm}$ and a pin diameter of $6 \mathrm{~mm}$. The sliding distance of wear test was maintened to be $650 \mathrm{~mm}$ for all tested samples. The weight loss and wear rate were measured to analysis the wear resistance of investigated samples depending upon the applied normal load and the recorded friction force. The thermal conductivity of the pure $\mathrm{Cu}$ and $\mathrm{Cu} / \mathrm{Gn}$ nanocomposites samples was measured by thermal coefficient meter (YBF-3, Korea) at room temperature.

\section{Results and discussion}

The morphology of as-received $\mathrm{Cu}$ and multilayer $\mathrm{Gn}$ powders has been investigated using SEM micrographs, as presented in Fig. 1. It can be observed that the $\mathrm{Cu}$ powder consists of particles in dendritic and irregular morphology (Fig. 1a), while the Gn particles have a flake shape layers stacked randomly upon each other, agglomerated, and attached in a multi-layer nanoplatelet structure, along with many voids in-between the stacked layers (Fig. 1b). The EDS result of the $\mathrm{Cu}$ powder revealed that the powder is highly pure $(\sim 100 \%)$ and no other elements are observed (Fig. 1c). Also, the EDS result of Gn powder (Fig. 1d) demonstrates the attendance of carbon only.

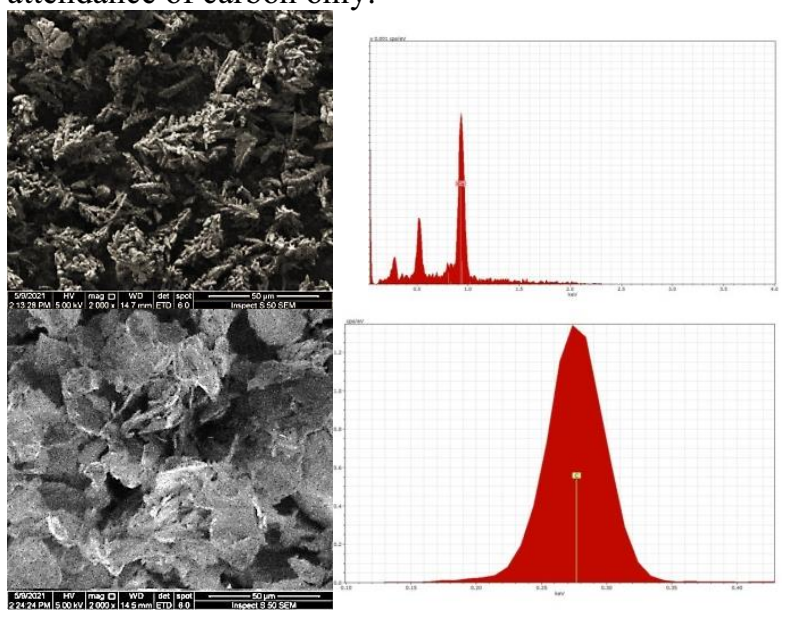

Fig. 1 Scanning electron micrographs of as received (a) $\mathrm{Cu}$ powder and (b) Gn powder.

The influence of $\mathrm{Gn}$ addition on the density values of the pure $\mathrm{Cu}$ and $\mathrm{Cu} / \mathrm{Gn}$ nanocomposites is shown in Table 1 . In general, the density of sintered samples is higher than that of pure $\mathrm{Cu}$. The maximum density of sintered samples has been obtained for the $\mathrm{Cu}-1 \mathrm{wt} \% \mathrm{Gn}$ nanocomposite sample ( $95.7 \%$ of theoretical) regardless of the lighter nature of $\mathrm{Gn}$. This is probably owing to the effect of Gn particles which may act as a lubricant agent during cold pressing [18].

Table 1. Influence of the varying in $\mathrm{Gn}$ additions on the densities of pure $\mathrm{Cu}$ and $\mathrm{Cu} / \mathrm{Gn}$ nanocomposites.

\begin{tabular}{|c|c|c|c|}
\hline Material & $\begin{array}{c}\text { Measured } \\
\text { density }\end{array}$ & $\begin{array}{c}\text { Theoretical } \\
\text { density }\end{array}$ & $\begin{array}{c}\text { Relative } \\
\text { density }\end{array}$ \\
\hline Pure $\mathrm{Cu}$ & 8.115 & 8.873 & 91.4 \\
\hline $0.5 \% \mathrm{Gn}$ & 8.357 & 8.906 & 93.8 \\
\hline $1 \% \mathrm{Gn}$ & 8.511 & 8.98 & 95.7 \\
\hline
\end{tabular}

Fig. 2 presents the optical micrographes of the pure $\mathrm{Cu}$ and $\mathrm{Cu} / \mathrm{Gn}$ nanocomposites produced by powder technology process. Here, the bright zones point to the $\mathrm{Cu}$ matrix and the dark zones identify the uniformly distributed $\mathrm{Gn}$ particles. It can be observed that $\mathrm{Cu}$ matrix and Gr particles could be evidently distinguished from these micrographs. Also, Gr particles are homogeneously distributed within the $\mathrm{Cu}$ matrix in most cases of the study. It is vital to note that numerous of the $\mathrm{Gr}$ particles were embedded in the $\mathrm{Cu}$ matrix while the rest of them were detected at the grain boundaries of the $\mathrm{Cu}$ matrix owing to the finer size of $\mathrm{Gn}$ particles, as shown in Fig. 2 (a-c). The embedded particles have a 
stable state as they do not have ability to rearrange themselves in the matrix. The homogeneous distribution of $\mathrm{Gn}$ within $\mathrm{Cu}$ matrix was achieved when the amount of $\mathrm{Gn}$ is $0.5 \mathrm{wt} \%$ and $1 \mathrm{wt} \%$ (see Fig. 2(b-c)). It can be concluded that the powder metallurgy technique may be appropriate for manufacturing nanocomposites at these amounts of Gn. It was reported that the strengthening effect of Gn particles in the metal matrix composites is because of the strong adhesion between $\mathrm{Gn}$ and $\mathrm{Cu}$ [19].
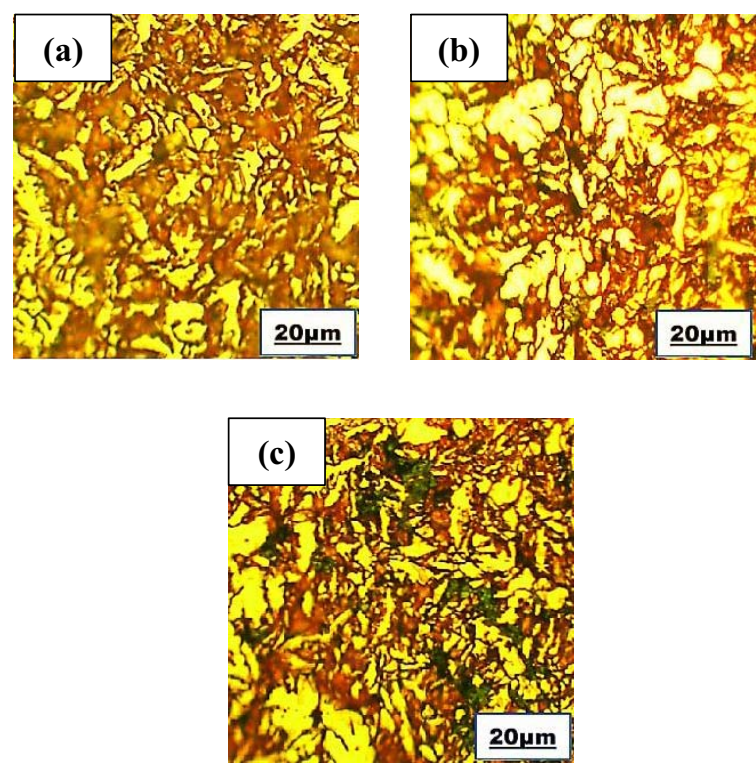

Fig. 2 Optical micrographs of: (a) Pure $\mathrm{Cu}$, (b) $\mathrm{Cu}-0.5 \mathrm{wt} \%$ $\mathrm{Gn}$, and (c) $\mathrm{Cu}-1 \mathrm{wt} \% \mathrm{Gn}$.

The EDS analysis of the produced nanocomposites is shown in Fig. 3. The results display the presence of $\mathrm{Cu}$, $\mathrm{C}$ and $\mathrm{O}$ only without any interfacial products, which confirm that no reactions occurred between $\mathrm{Cu}$ and $\mathrm{Gn}$ during the sintering process.

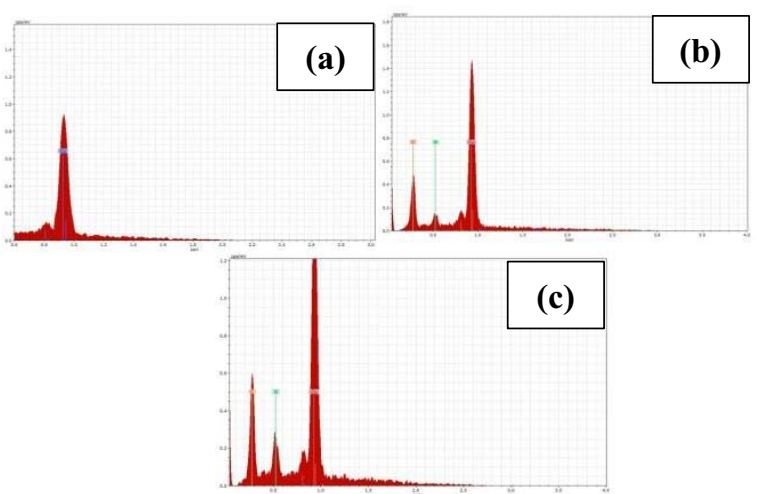

Fig. 3 EDS results of: (a) Pure $\mathrm{Cu}$, (b) $\mathrm{Cu}-0.5 \mathrm{wt} \% \mathrm{Gn}$, (c) $\mathrm{Cu}-1 \mathrm{wt} \% \mathrm{Gn}$, (d) $\mathrm{Cu}-1.5 \mathrm{wt} \% \mathrm{Gn}$, and (e) $\mathrm{Cu}-2 \mathrm{wt} \% \mathrm{Gn}$.

The influence of the Gn content on the thermal conductivity of $\mathrm{Cu} / \mathrm{Gn}$ nanocomposites has been studied in this work. The addition of Gn particles plays an important role in increasing the thermal conductivity of $\mathrm{Cu}$ matrix. This is due to the high thermal conductivity of $\mathrm{Gn}$. The thermal conductivity of pure $\mathrm{Cu}$ was measured to be $371 \mathrm{~W} / \mathrm{m} . \mathrm{K}$, while this value increased slightly to be $382 \mathrm{~W} / \mathrm{m} . \mathrm{K}$ ( $3 \%$ improvement) by adding $0.5 \mathrm{wt} \%$ of $\mathrm{Gn}$. This increase due to uniform dispersion of a little amount of added $\mathrm{Gn}$ within $\mathrm{Cu}$ matrix (see Fig. $2 b$ ), which limits the effect of some factors like the grain size and thermal expansion mismatch of the materials. The higher grain size of Gn particles can efficiently compensate the effect of imperfections like pores and holes created in the $\mathrm{Cu} / \mathrm{Gn}$ nancomposites throughout sintering process, which may advantageously lead to the movement of phonons and in turn the enhancement of thermal conductivity [20]. The highest value was found after adding $1 \mathrm{wt} \%$ of $\mathrm{Gn}(402 \mathrm{~W} / \mathrm{m} . \mathrm{K})$ with $8 \%$ improvement percentage.

The micro-hardness values of pure $\mathrm{Cu}, 0.5 \mathrm{wt} \%$ $\mathrm{Gn}$ and $1 \mathrm{wt} \%$ Gn samples were measured to be $41 \pm$ $1.8,50 \pm 2.3$, and $61 \pm 2.5$, respectively. It can be noted from these data that the hardness values of nanocomposites are greater than those of pure $\mathrm{Cu}$ due to the higher mechanical properties of Gn. Thus, a small amount of $\mathrm{Gn}$ particles added to the $\mathrm{Cu}$ matrix significantly improved the hardness of the produced composites. Among all samples, the highest value of 61 $\mathrm{HV}$ was observed for $\mathrm{Cu}-1 \mathrm{wt} \% \mathrm{Gn}$ sample. This increase is associated with the strong mechanical bonding between $\mathrm{Cu}$ matrix and $\mathrm{Gn}$ particles for the entire range of reinforcement adding [18], along with the homogeneous microstructure observed in the $\mathrm{Cu}$ $1 \mathrm{wt} \%$ Gn sample (see Fig. 2c). It is vital to mention here that the dispersion hardening is the major mechanism for strengthening that is responsible for the development in the hardness values of the present nanocomposites [21].

Table 2 presents the most important values obtained through the wear test for pure $\mathrm{Cu}$ and $\mathrm{Cu} / \mathrm{Gn}$ nanocomposites samples. It can be observed that the pure $\mathrm{Cu}$ sample has the largest loss of mass and the most rate of wear. On the other hand, $\mathrm{Cu} / \mathrm{Gn}$ nanocomposites showed superior wear resistance compared to pure $\mathrm{Cu}$ sample owing to the higher mechanical and lubricating characteristics of $\mathrm{Gn}$ particles. This is an expected outcome depending upon the hardness measurements and highly agreed with Archard's wear equation as the increase in hardness led to develop the wear resistance of investigated samples [22]. The improvement of wear resistance with increasing Gn content was achieved as the wear rate was found to decrease significantly. The lowest wear rate was observed for $\mathrm{Cu}-1 \mathrm{wt} \% \mathrm{Gn}$ sample with a wear rate of $2.43 * \mathbf{1 0}^{-\mathbf{4}} \mathrm{mm}^{3} / \mathrm{Nm}$ at an applied load of $20 \mathrm{~N}$. The interlayer shearing in $\mathrm{Gn}$ can be considered as the main mechanism responsible for diminishing wear rate. The distant $\mathrm{Gn}$ layer acts as a self-solid lubricant which could play a key role as a lubricant between the contact surfaces and in turn to inhibit the additional delamination of the material. In other words, the Gn layer prevents the metal to metal contact as it has an ability to form a lubricating zone on the disk causing a drastic decrease in wear rate. It was 
pointed out that the shear strength of $\mathrm{Gn}$ film is considerably low, which can reduce the wear and friction effectively. Moreover, the high value of microhardness for $\mathrm{Cu}-1 \mathrm{wt} \% \mathrm{Gn}$ sample is another important factor, which may act to extend the life of $\mathrm{Cu} / \mathrm{Gn}$ nanocomposites during wear test [18].

Table 2 Results of wear test for pure $\mathrm{Cu}$ and $\mathrm{Cu} / \mathrm{Gn}$ nanocomposites

\begin{tabular}{|c|c|c|c|c|}
\hline Material & $\begin{array}{c}\text { Wear } \\
\text { mass loss } \\
(\mathrm{g})\end{array}$ & $\begin{array}{c}\text { Volume } \\
\text { loss } \\
\left(\mathrm{mm}^{3}\right)\end{array}$ & $\begin{array}{c}\text { Wear rate } \\
\left(\mathrm{mm}^{3} / \mathrm{Nm}\right)\end{array}$ & $\begin{array}{c}\text { Improvement } \\
(\%)\end{array}$ \\
\hline Pure $\mathrm{Cu}$ & 0.0045 & 0.5033 & $5.126^{*} 10^{-4}$ & - \\
\hline $0.5 \% \mathrm{Gn}$ & 0.0027 & 0.3031 & $3.108 * 10^{-4}$ & 40 \\
\hline $1 \% \mathrm{Gn}$ & 0.0023 & 0.259 & $2.656 * 10^{-4}$ & 49 \\
\hline
\end{tabular}

\section{References}

1. D. Jan, O. Piotr, M. Wojciech, et al., Mater. Sci. Eng. A628 (2015).

2. G.F. Celebi Efe, I. Altinsoy, M. Ipek, S. Zeytin, C. Bindal, Kovove Materialy 49, 2 (2011).

3. G.S. Upadhyaya, Sintered metallic and ceramic materials preparation, properties and applications, vol. 1 (J. Wiley \& Sons Inc., New York, NY, USA, 1999).

4. C. Zou, Z. Chen, E. Guo, et al., RSC Adv. 8, (2018).

5. X. H. Guo, K. X. Song, Liang S H, et al. Tribology Transactions 57(2) (2014) .

6. V. Rajkovic, D. Bozic, J. Stasic, H.W. Wang, M.T. Jovanovic, Powder Technol. 268 (2014).

7. A.A. Balandin, Nature Materials 10 (2011).

8. A.K. Geim, K.S. Novoselov, Nature Materials 6 (2007).

9. X. Du, I. Skachko, A. Barker, E.Y. Andrei, Nature Nanotechnology 3 (2008).

10. M.A. Jeluen Li, D.H. Adamson, Chem. Mater. 19 (2007).

11. J. Hwang, T. Yoon, S.H. Jin, J. Lee, T.-S. Kim, S.H. Hong, et al., Adv. Mater. 25 (46) (2013).

12. W.J. Kim, T.J. Lee, S.H. Han, Carbon 69 (2014).

13. C.L.P. Pavithra, B.V. Sarada, K.V. Rajulapati, T.N. Rao, G. Sundararajan, Sci. Rep. 4 (2014).

14. M. Li, H. Che, X. Liu, S. Liang, H. Xie, J. Mater. Sci. 49 (10) (2014).

15. J. Dutkiewicz, P. Ozga, W. Maziarz, J. Pstru_s, B. Kania, P. Bobrowski, et al., Mater. Sci. Eng. A 628 (2015).

16. Standard Practice for Micro-etching Metals and Alloys, ASTM International, Designation: E407-07 (2015).
17. Standard Test Method for Wear Testing with a Pin on Disk. ASTM Standard, Désignation: G 99-95a (2000).

18. C. Ayyappadas, A. Muthuchamy, A. Raja Annamalai, Dinesh K. Agrawal, Advanced Powder Technology 28 (2017).

19. X. Gao, Y. Hongyan, G. Erjun, Z. Hong, et al., Mater. Des. 94 (2016).

20. W. Jian, G. Li-na, L. Wan-ming, et al., New Carbon Materials, 34 (2) (2019).

21. T. Varol, A. Canakci, Met. Mater. Int. 21 (4) (2015).

22. H.G. Prashantha Kumar, M. Anthony Xavior, Trans. Indian Inst. Met. 69 (2) (2016). 